\title{
Preliminary Weight Savings Estimate for a Commercial Transport Wing Using Rod-stiffened Stitched Composite Technology
}

\author{
Andrew E. Lovejoy ${ }^{1}$ \\ NASA Langley Research Center, Hampton, VA 23681
}

\begin{abstract}
A structural concept called pultruded rod stitched efficient unitized structure (PRSEUS) was developed by the Boeing Company to address the complex structural design aspects associated with a pressurized hybrid wing body (HWB) aircraft configuration. While PRSEUS was an enabling technology for the pressurized HWB structure, limited investigation of PRSEUS for other aircraft structures, such as circular fuselages and wings, has been done. Therefore, a study was undertaken to investigate the potential weight savings afforded by using the PRSEUS concept for a commercial transport wing. The study applied PRSEUS to the Advanced Subsonic Technology (AST) Program composite semi-span test article, which was sized using three load cases. The initial PRSEUS design was developed by matching cross-sectional stiffnesses for each stringer/skin combination within the wing covers, then the design was modified to ensure that the PRSEUS design satisfied the design criteria. It was found that the PRSEUS wing design exhibited weight savings over the bladestiffened composite AST Program wing of nearly 9\%, and a weight savings of $49 \%$ and $29 \%$ for the lower and upper covers, respectively, compared to an equivalent metallic wing.
\end{abstract}

\section{Introduction}

$\mathrm{T}$ HE pultruded rod stitched efficient unitized structure (PRSEUS) is a structural concept that was developed by the Boeing Company to address the complex structural design aspects associated with a pressurized hybrid wing body (HWB) aircraft configuration. The HWB has long been a candidate studied in an effort to increase the fuel efficiency of aircraft as it has the advantage of simultaneously increasing both fuel efficiency and payload. ${ }^{1,2}$ As a result, the use of PRSEUS has also been a focus of Environmentally Responsible Aviation (ERA) Project at National Aeronautics and Space Administration (NASA) Langley Reseach Center (LaRC), however, in that effort the structures development has primarily addressed the pressurized, non-circular fuselage portion of the HWB.

While PRSEUS was an enabling technology for the pressurized HWB structure, the potential for PRSEUS to provide performance and weight advantages to other aircraft structures, such as wings, had limited investigation. Therefore, a study was undertaken to investigate the potential gains that can be achieved by using PRSEUS as the structural concept for a conventional commercial transport wing. The wing investigated in this study is the 220passenger transport aircraft composite semi-span test article that was tested at LaRC as part of the Advanced Subsonic Technology (AST) Program, ${ }^{3-5}$, hence forth called AST. Three load cases were used to size the stitched, blade-stiffened composite AST Program semi-span, and were the same load cases used to develop a PRSEUS semispan having similar capability. The design load cases were $2.5 \mathrm{G}$ up bending, $-1.0 \mathrm{G}$ down bending, and braked roll. Bending moment, shear and torsion diagrams for design limit load (DLL) are shown in Fig. 1, and are defined in the wing elastic axis coordinate system shown in the figure. This paper presents an initial study that evaluates the potential weight savings for a conventional transport wing constructed using the PRSEUS concept.

\section{PRSEUS Concept}

PRSEUS is an integral structural concept where skins, frames, stringers and tear straps are all stitched together, then infused and cured in an out-of-autoclave process. ${ }^{6}$ The pressurized fuselage structure version of the PRSEUS

\footnotetext{
${ }^{1}$ Research Aerospace Engineer, Structural Mechanics and Concepts Branch, 8 West Taylor Street, Mail Stop 190, NASA Langley Research Center, Hampton, VA, 23681, Senior Member AIAA.
}

1

American Institute of Aeronautics and Astronautics 
concept is shown in Fig. 2. This concept has evolved out of stitching technology development from several NASABoeing and Air Force Research Laboratory (AFRL)-Boeing programs beginning in the 1990's. The key to the PRSEUS concept is the pre-cured, pultruded rod that is contained within the stringer wrap plies and which passes through the frames, providing an uninterrupted load path. At the same time, the full depth frame stiffener is also continuous, except for the keyhole through which the stringer passes, providing an uninterrupted load path in the direction perpendicular to the stringer. These efficient structural stiffening members provide the majority of the panel stiffness, permitting the use of minimum skin thickness for many applications. For example, typical PRSEUS stringer and frame cross-sections examined for pressurized HWB fuselage type structure are shown in Fig. 3, where the skin is minimum gage and the stringer and frame are the main load carrying components. ${ }^{7,8}$ Typical stringers in the HWB fuselage design use only a single stack for the stringer, which creates a two-stack web and a single-stack wrap and flange.

The PRSEUS concept uses dry warp-knit fabric materials stitched together to create a preform of the full structural panel, so that all materials can be co-cured with minimal use of inner moldline tooling. Skins, flanges, and webs comprise layers of graphite material forms that are pre-knitted into multi-ply stacks. Multiple stacks of the warp-knit material are used to build up the desired part thickness and configuration. The rod stiffener for the PRSEUS design is a pre-cured unidirectional graphite/epoxy. In order to maintain the panel geometry during fabrication, frames and stringers are placed in a stitching tool, and then the skin stack(s) are placed in the stitching tool to prepare for stitching of the assembly. The assembly is stitched together, and then the full assembly is moved to a curing tool for resin infusion and consolidation in an oven using controlled atmospheric pressure resin infusion (CAPRI) process from Boeing. ${ }^{6,9}$ Since the stiffener flanges are stitched to the skin, no mechanical fasteners are used for joining the assembly structural elements.

\section{PRSEUS Semi-Span Wing Design Approach}

The PRSEUS semi-span wing was designed in accordance with the applicable design criteria developed for the composite AST semi-span wing, which are provided in Ref. 3. Design requirements for the PRSEUS semi-span primarily include strength, stability, and deflection, with damage tolerance and manufacturability included to a lesser degree. Although PRSEUS can support post-buckled skins due to the presence of the flange stitching, the criteria such as no skin buckling permitted below design ultimate load (DUL) was retained, even though this will lead to a more conservative PRSEUS design. These criteria were used so that there will be a more direct comparison with the blade-stiffened design. In addition, several design criteria were imposed on the PRSEUS wing design to simplify the design process, and to capture the current state of the manufacturing process. The design criteria were:

- Rods were of uniform cross-section along the length of each stringer.

- Tear strap transitions had single-stack drops.

- Stringer height changes were limited to 0.25 inches between adjacent rib bays, where the stringer height on one side of a rib can exceed the height on the other side of the rib by a maximum of 0.25 inches.

- Stringer height changes were tapered on the side of the rib having the stringer with the smaller height, and occur, at minimum, across one third of the bay length.

- Upper cover skin and stringer webs used the same stack material as the AST wing upper cover and stringer webs.

- Lower cover skin and stringer webs used the same stack material as the AST wing lower cover.

The baseline finite element model for the PRSEUS design was derived from the AST semi-span model shown in Fig. 4. This initial PRSEUS wing study focuses only on the skins and stringers of the upper and lower cover panels of the semi-span shown in Fig. 5, as these are the components for which PRSEUS is anticipated to have the greatest benefit. For the baseline PRSEUS design, the AST semi-span stringer spacing of 7.6 inches, and the rib spacing ranging from 26 inches to 30 inches, was retained. The stringer and rib identification is shown in Figure 6, where stringer \#1 is closest to the leading edge. Structural features of the AST semi-span design are replaced by PRSEUS features in the following manner. The first structural feature is that the AST semi-span has blade stringers, which are oriented along the span, and which represent significant span-wise load carrying structure. The blade stringers are replaced by the PRSEUS rod-stiffened stringer. The second structural feature is that in a typical wing, the wing 
covers are attached to ribs at numerous span-wise stations. In the AST semi-span, the rib webs are scalloped to allow the blade stiffeners to pass through the ribs, and the rib webs are attached to the covers using intercostal clips. ${ }^{1}$ The intercostal clips are connected to the covers via stitching through the intercostal flanges, with tabs that are bonded to the blade stiffeners, as shown in Fig. 7. Each intercostal clip is a separate pre-assembly that spans between two stringers, and is incorporated into the complete AST wing cover assembly. For the PRSEUS semi-span design developed in this paper, the foam-filled frame section used for pressurized fuselage structure, as shown in Fig. 3, is replaced with an integral blade stiffener, as shown in Fig. 8. The blade stiffener is fabricated from stitched stack material only, and is stitched to the rest of the PRSEUS components in a manner similar to the foam-filled frame. These integral blade stiffeners replace the individual intercostal clips that are in the rib locations in AST semi-span design. The rod-stiffened stringers pass through the keyholes in the blade stiffeners, similar to what is done with the foam-filled frames for pressurized fuselage structure, maintaining the continuity of the stiffeners in both directions. For the purpose of this initial PRSEUS wing design study, it is assumed that this PRSEUS frame element is identical in design to the AST intercostals, resulting in no change being made in the finite element model to represent the PRSEUS frames.

The initial PRSEUS baseline model was sized by matching the cross-sectional stiffness of the PRSEUS structure to the stiffness of the blade stringer/skin in the AST semi-span. The AST upper cover skin, upper stringers, and lower cover skin are fabricated from stacks that are 0.055 inches thick. The AST lower cover stringers are fabricated from braided tubes that are collapsed to form a fabric that is 0.048 inches thick. The PRSEUS design utilizes 0.055inch thick stacks for the upper and lower cover skins and stringers. As mentioned in the additional PRSEUS constraints, the lower cover skin and stringers utilize the lower cover skin material of the AST wing. Material properties used in the analyses are defined in Table 1. Sketches for two typical upper cover stringer sections along stringer 5, where stiffness matching was applied, are shown in Figs. 9 and 10. Equivalent sections comprise the stringers and the skin that extends to the mid-bay on either side of the stringer. The PRSEUS design was estimated by varying the PRSEUS design variables to match axial and bending stiffness, with axial stiffness given priority over the out-of-plane bending, and with the in-plane bending given the lowest priority for matching. This stiffness matching was instituted for each stringer region between rib sets. The resulting designs were incorporated into the finite element model. Due to the constraints on the PRSEUS design and the discrete nature of the cross-section components, the area stiffness errors ranged from $-4.01 \%$ to $7.14 \%$, however, the majority of the regions were within $-0.8 \%$ and $2.0 \%$. The AST cover designs are shown in Figure 11, and the baseline PRSEUS cover designs that are developed using this stiffness matching approach are shown in Fig. 12. These two figures provide the keys to identify the stringer definitions and the skin thicknesses, where the PRSEUS wing skin thicknesses were kept identical to the AST wing covers.

The identical wing skin thicknesses were selected with the expectation that stiffness matching would lead to similar load distribution, and therefore, the skin buckling criteria would be satisfied directly as a result of similarity to the AST wing. The rod diameter is kept constant along the length of each stringer, as previously mentioned in the design criteria, and is a consequence of the current method of rod manufacture whereby the rod is pultruded. The uniform rod cross-section is also necessary for the current manufacturing process, where the rod is pulled through the stringer wrap pockets once the the stringer preform is loaded into the stitching tool, and the rod must pass fully through the stitching tool. Using nonuniform rod cross-sections will require further manufacturing development. For the PRSEUS designs in this study, the lower cover stringers \#1,\#2, and \#3 and the upper cover stringers \#1 and \#2 have 0.5 inch diameter rods, while the remaining stringers have 0.625 inch diameter rods.

Since several of the stringers terminate due to approaching the leading or trailing edge spars, such as stringers \#2 and \#10 terminating at rib \#9 of the upper cover, a means to terminate the rod-stiffened stringer was required. In the AST wing, some of the stringers were kept at constant height, while others were tapered in height. A similar approach was applied to the PRSEUS wing. In the case of the PRSEUS wing, the constant-height stringers were run to the rib web without modification to the stringer cross-section. However, a means to define the tapered-height PRSEUS stringers was also required. In a previous study, a machined taper shown in Fig. 13 was used to transition the load out of the rods and into the repair structural components for a PRSEUS HWB fuselage panel with a severed stringer. ${ }^{10}$ This approach was deemed to be an appropriate solution for terminating stringers in the PRSEUS wing cover design, and was adopted for the PRSEUS baseline. As discussed in the results section, this approach was modified to soften up the bending stiffness of the stringer termination region to yield more satisfactory strain values where needed. 


\section{Finite Element Analysis}

The baseline AST and PRSEUS semi-span finite element models were analyzed using the MSC/NASTRAN finite element code. ${ }^{11}$ Linear static analysis was performed using the three load cases, with all nodes at the root of the semi-span being restrained for the three translational degrees of freedom. In order to simplify the load introduction for the analyses, the models were analyzed using the actuator loads that were developed to match the load curves shown in Fig. 1, and that were applied to the AST semi-span during testing. The actuator locations and associated loads for the three load cases are presented in Fig. 14 and Table 2, respectively. Presented loads were in terms of DUL, which was defined as 1.5 times DLL. The AST semi-span was modeled using shell elements with the appropriate thicknesses and offsets. The PRSEUS semi-span was modeled using shell elements with the appropriate thicknesses and offsets throughout, with the exception of the rod portion of the stringer that was modeled using beam elements. The PRSEUS stringer shell elements representing the web modeled the portion of the stringer from the flange to the bottom of the rod/wrap region. The rod/wrap region was represented using beam elements having equivalent axial and bending stiffnesses of the rod/wrap region. Offsets were applied to the beam elements to place the centroid of the rod/wrap region a the correct location. As needed, modifications to the PRSEUS model were made to design parameters such as rod diameter, stringer height, number of stacks (skin, stringer, blade), etc. to develop a refined PRSEUS semi-span design.

\section{Results and Discussion}

The AST and PRSEUS baseline semi-span wings were evaluated in accordance with the design criteria using the DUL response. In particular, emphasis was placed on strength, stability and deflection. Strength was evaluated in terms of principal strains by means of tension and compression allowable strain values. Allowable principal strain values are given in Table 3 for the upper and lower cover skin materials, and are taken from Ref. 4. These values encompass various modes of failure such as impact damage, discrete source damage, and repair. Reference 3 indicates that the $2.5 \mathrm{G}$ up bending load case primarily sized the upper and lower covers, so that was the first load case examined. The $2.5 \mathrm{G}$ up bending maximum and minimum principal strains for the AST and the PRSEUS baseline lower and upper covers are shown in Fig. 15, and Fig. 16, respectively. In the figures, the lower cover strains around the access holes were ignored since the local build-ups around the holes were not represented in this global response model. Examining the strains in the remainder of the AST cover skins verified the positive margins for both skins. However, the strains in the PRSEUS baseline lower cover skin exceeded the design allowable values at the termination of stringer \#10, which yielded a margin of safety for the lower cover skin of -0.27 . In an effort to reduce the strain in the bay adjacent to the stringer \#10 runout, the skin thickness was increased from 9 stacks to 11 stacks, but the resulting margin of safety remained negative, with a value of -0.14 . Further modifications to the PRSEUS cover designs were required to yield positive margins.

The stringer runouts in the PRSEUS wing were the same as runouts used in the AST wing with either a uniform height or tapered height. The method to model the tapered runout was modeled in the same way as a previous PRSEUS repair study. However, it appears that this taper was too short, and that the resulting PRSEUS stiffener was to stiff, so that additional load was drawn to the stringer termination. Therefore, the stringer taper was progressively modified to make the runout be significantly less stiff in bending, by making the taper much longer and by dropping off stacks in the taper. Lower cover representations in the PRSEUS model are shown in Fig. 17, where the taper on stringer \#2 represents the baseline taper, which has been modified to the softer stringer taper shown for stringer \#10. The margin of safety improved, but was still not positive, with a value of -0.09. Examination of the displacements for the AST wing and the modified PRSEUS wing design indicated that the vertical tip deflection for the PRSEUS wing exceeded that for the AST wing by $4.9 \%$ for the $2.5 \mathrm{G}$ up bending load case. Displacement contours indicated that there was a general increase in flexibility for the PRSEUS design. Therefore, the PRSEUS model was updated by adding additional tear strap stacks in the regions where the stiffness matching showed the PRSEUS design exhibited the largest negative axial stiffness differences. This final PRSEUS design is shown in Fig. 18, where changes to the stringer tear straps are identified by stringer designations shown in red. Principal strains for this final PRSEUS model are shown in Fig. 19. The lower cover strain margin of safety for this model was 0.01, resulting in positive margins of safety for the cover skin strains. The stressess in the stringers were examined, and the minimum margins of safety in the rods were in excess of 1.9 using ultimate tension and compression strength allowables of $390 \mathrm{ksi}$ and $200 \mathrm{ksi}$, respectively. The final PRSEUS design tip deflection for the $2.5 \mathrm{G}$ up bending load case exceeded the AST design tip deflection by $4.2 \%$. 
The 2.5G up bending load case was then examined for skin buckling. The AST wing satisfied the buckling criteria with a minimum margin of safety of 0.18 in a 5-stack bay, based on a buckling running load of $\mathrm{N}_{\mathrm{x}}=-17157 \mathrm{lb}$./in. from Ref. 4 . The final PRSEUS design has a minimum skin buckling margin of safety of 0.15 . This result was expected based on using the AST wing skin thicknesses for the PRSEUS design, as previously mentioned. Examination of the other two load cases exhibited that the margins were positive, and reaffirms that the $2.5 \mathrm{G}$ up bending load case sizes the upper and lower covers for the semi-span wing.

A comparison of the AST and PRSEUS wing designs demonstrated that weight savings over the blade-stiffened composite AST wing can be achieved by using the PRSEUS concept. In this study, since only the skins and stringers of the cover panels were modified for the PRSEUS design, the weight comparison was performed using only skins and stringers of the semi-span wing cover panels. Examination of the stiffness-matched PRSEUS baseline regions showed individual region weight savings from 8-13\% when compared to the AST design. Actual weight savings are shown in Table 4 for the AST, PRSEUS baseline and PRSEUS final designs. The cover panels were attached to the spar webs using integral caps along the leading and trailing edges of the covers. An overhang portion was located outboard of the integral spar caps. During the design process, the overhang and region just inboard of the integral caps were not included. In Table 4, the columns identified as "All" include the entire skin and stringers, while those labeled as "Acreage" did not include the overhang and integral cap portons of the covers. The PRSEUS baseline design when compared to the AST design exhibited an overall weight savings of $8.67 \%$ and $9.08 \%$ for the lower and upper covers, respectively. This value fell within the anticipated weight savings based on examination of the stiffness-matched regions. However, since this PRSEUS baseline design did not satisfy the design criteria, the model was modified to develop the final PRSEUS design. As shown in the table, this final design exhibited overall weight savings of $8.27 \%$ and $8.13 \%$ for the lower and upper covers, respectively, when compared to the AST design. Acreage weight comparison showed that this weight savings increased to $9.11 \%$ and $8.86 \%$ for the lower and upper covers, respectively. Therefore, the final PRSEUS design resulted in a weight savings of approximately $9 \%$ when compared to the AST blade-stiffened composite. Also shown in Table 4 are estimated weights for a comparable metallic wing based on the weight savings demonstrated in Refs. 3 and 4, where the values shown for the AST covers were based on the reference data. Based upon this estimated metallic wing weight, the PRSEUS wing demonstrated a weight savings of approximately $49.7 \%$ and $30.1 \%$ for the lower and upper covers, respectively.

\section{Conclusions}

A PRSEUS semi-span wing was designed to be equivalent to the AST Program semi-span tested at NASA Langley Research Center. Based on a stiffness-matching method, the initial weight saving estimate achieved by using the PRSEUS construction was about 9\% compared to the AST wing. The final PRSEUS design that was developed from the baseline in order to satisfy the design criteria, demonstrated a weight savings of just over $8 \%$ for the covers, and about $9 \%$ for the acreage (skin and stringers) portion of the covers when compared to the AST wing. In addition, when compared to an estimated metallic wing weight based on data in the literature, the PRSEUS design demonstrated weight savings of about 50\% and $30 \%$ for the lower and upper covers, respectively. The demonstrated weight savings were achieved even though there was restrictive design criteria imposed on the PRSEUS design to simplify the design process, and also take into account the current manufacturing capabilities. It was found that care must be taken when terminating the PRSEUS stringer to soften up the bending stiffness so as not to draw excessive load to the runout region. Potentially, if restrictions on local buckling and size constraints (such as rod diameters and stringer height variation) are relaxed, and if there were improved manufacturing techniques that will permit the use of nonuniform rod cross-sections, the weight savings observed by using PRSEUS will increase. Also, since the blade frame in the PRSEUS wing cover does not carry significant load along the length of the frame, the frame only needs sufficient height to include the stringer keyhole and still maintain shape during the manufacturing process.

\section{References}

\footnotetext{
${ }^{1}$ Liebeck, R., "Design of the Blended-Wing-Body Subsonic Transport", Paper AIAA-2002-0002, 40th AIAA Aerospace Sciences Meeting \& Exhibit, Reno, Nevada, January 14-17, 2002.

${ }^{2}$ Liebeck, R., "Design of the Blended Wing Body Subsonic Transport", Journal of Aircraft, Vol. 41, No. 1, January-February, 2004, pp. 10-25.

${ }^{3}$ Ayale, Andrew and Thrash, Patrick, "AST Composite Wing Program: Semi-Span Wing Fabrication Tests and Supporting Technology", Final Report for NASA Contract NASl-20546, Long Beach, CA, 2000.

${ }^{4}$ Moon, Darwin and Velicki, Alex, "AST Composite Wing Program: Full-Scale Stitched/Resin Film Infused Wing Design, Fabrication and Structural Verification", Final Report for NASA Contract NASl-20546, Long Beach, CA, 2000.
} 
${ }^{5}$ Jegley, Dawn C., Bush, Harold G., and Lovejoy, Andrew E., "Structural Response and Failure of a Full-Scale Stitched Graphite-Epoxy Wing." Journal of Aircraft, Vol. 40, No. 6, November-December 2003, pp. 1192-1199.

${ }^{6}$ Velicki, A., "Damage Arresting Composites for Shaped Vehicles, Phase I Final Report," NASA CR-2009-215932, September 2009.

${ }^{7}$ Lovejoy, Andrew E., "PRSEUS Pressure Cube Test Data and Response", NASA/TM-2013-217795, May 2013.

${ }^{8}$ Yovanov, Nicolette, Lovejoy, Andrew, Baraja, Jaime, and Gould, Kevin. "Design, Analysis and Testing of a PRSEUS Pressure Cube to Investigate Assembly Joints," 2012 Airworthiness \& Sustainment Conference, Baltimore, Maryland, April 2-5, 2012.

${ }^{9}$ Velicki, A., Yovanof, N., Baraja, J., Linton, K., Li, V., Hawley, A., Thrash, P., DeCoux, S. and Pickell, R., "Damage Arresting Composites for Shaped Vehicles - Phase II Final Report,” NASA CR-2011-216880, January 2011.

${ }^{10}$ Przekop, Adam, and Jegley, Dawn C., "Evaluation of a Metallic Repair on a Rod-Stiffened Composite Panel", Journal of Aircraft, Vol. 51, No. 3, 2014, pp. 792-804.

${ }^{11}$ MSC Corporation, http://www.mscsoftware.com/product/msc-nastran.

Table 1. Material properties used for in the PRSEUS design study.

\begin{tabular}{|c|c|c|c|c|c|c|c|c|c|}
\hline \multirow[b]{2}{*}{ Material } & \multicolumn{4}{|c|}{ Compression Values } & \multicolumn{4}{|c|}{ Tension Values } & \multirow[b]{2}{*}{$\begin{array}{l}\text { Density } \\
\left(\mathbf{l b} / \text { in }^{3}\right)\end{array}$} \\
\hline & $\begin{array}{c}\mathbf{E}_{\mathbf{x}} \\
(\mathbf{M s i})\end{array}$ & $\begin{array}{c}\mathbf{E}_{\mathbf{y}} \\
(\mathbf{M s i})\end{array}$ & $\begin{array}{c}\mathbf{G}_{\mathbf{x y}} \\
(\mathrm{Msi})\end{array}$ & $\begin{array}{c}\text { Poisson's } \\
\text { Ratio }\end{array}$ & $\begin{array}{c}\mathbf{E}_{\mathbf{x}} \\
(\mathbf{M s i})\end{array}$ & $\begin{array}{c}\mathbf{E}_{\mathbf{y}} \\
(\mathbf{M s i})\end{array}$ & $\begin{array}{c}\mathbf{G}_{\mathbf{x y}} \\
(\mathrm{Msi})\end{array}$ & $\begin{array}{c}\text { Poisson's } \\
\text { Ratio }\end{array}$ & \\
\hline $\begin{array}{l}\text { Upper Cover Skin } \\
\text { and Stringers }\end{array}$ & 9.24 & 4.67 & 2.27 & 0.397 & 10.28 & 5.09 & 2.48 & 0.403 & 0.057 \\
\hline Lower Cover Skin & 10.48 & 4.82 & 2.27 & 0.397 & 12.12 & 5.15 & 2.48 & 0.403 & 0.057 \\
\hline $\begin{array}{l}\text { Lower Cover } \\
\text { Stringers }\end{array}$ & 9.28 & 5.86 & 2.41 & 0.307 & 10.24 & 5.43 & 4.41 & 0.291 & 0.057 \\
\hline Rod & 18.5 & N/A & N/A & 0.3 & 21.3 & N/A & N/A & 0.3 & 0.057 \\
\hline
\end{tabular}

Table 2. AST semi-span test load actuator values.

\begin{tabular}{|c|c|c|c|}
\hline Actuator & $\begin{array}{c}\text { Load Case 1 } \\
\mathbf{( - 1 . 0 G} \text { Down Bending) } \\
\text { (lbs.) }\end{array}$ & $\begin{array}{c}\text { Load Case 2 } \\
\mathbf{( 2 . 5 G ~ U p ~ B e n d i n g ) ~} \\
\text { (lbs.) }\end{array}$ & $\begin{array}{c}\text { Load Case 3 } \\
\text { (Braked Roll) } \\
\text { (lbs.) }\end{array}$ \\
\hline \hline 1 & $-9,000$ & 40,500 & $-1,500$ \\
\hline 2 & $-45,000$ & 99,750 & $-3,000$ \\
\hline 3 & $-33,000$ & $-3,000$ & $-1,500$ \\
\hline 4 & 12,000 & 21,000 & $-3,000$ \\
\hline 5 & $-9,000$ & 15,000 & $-12,000$ \\
\hline 6 & 17,250 & $-45,000$ & $-17,250$ \\
\hline $7 \mathrm{a}$ & $\mathrm{N} / \mathrm{A}$ & $\mathrm{N} / \mathrm{A}$ & 186,675 \\
\hline $7 \mathrm{~b}$ & $-4,500$ & 45,000 & $\mathrm{~N} / \mathrm{A}$ \\
\hline 8 & $-14,250$ & 6,000 & 15,000 \\
\hline
\end{tabular}


Table 3. Cover skin principal strain allowable values.

\begin{tabular}{|c|c|c|c|c|}
\hline \multirow{2}{*}{ \# of Stacks } & \multicolumn{2}{|c|}{ Upper Cover } & \multicolumn{2}{c|}{ Lower Cover } \\
\cline { 2 - 5 } & $\begin{array}{c}\text { Compression } \\
\text { (micro-in./in.) }\end{array}$ & $\begin{array}{c}\text { Tension } \\
\text { (micro-in./in.) }\end{array}$ & $\begin{array}{c}\text { Compression } \\
\text { (micro-in./in.) }\end{array}$ & $\begin{array}{c}\text { Tension } \\
\text { (micro-in./in.) }\end{array}$ \\
\hline \hline 2 & -3910 & 5118 & -3381 & 4867 \\
\hline 3 & -3910 & 5118 & -3381 & 4867 \\
\hline 4 & -3910 & 5118 & -3381 & 4867 \\
\hline 5 & -3910 & 5118 & -3381 & 4867 \\
\hline 6 & -3941 & 5118 & -3407 & 4867 \\
\hline 7 & -4268 & 5118 & -3690 & 4867 \\
\hline 8 & -4483 & 5118 & -3876 & 4867 \\
\hline 9 & -4606 & 5118 & -3982 & 4867 \\
\hline 10 & -4606 & 5118 & -3982 & 4867 \\
\hline 11 & -4606 & 5118 & -3982 & 4867 \\
\hline 12 & -4606 & 5118 & -3982 & 4867 \\
\hline
\end{tabular}

Table 4. Weight comparisons for semi-span wing designs.

\begin{tabular}{|c|c|c|c|c|c|}
\hline \multirow{2}{*}{ Design } & \multicolumn{2}{|c|}{ Weight (lbs.) } & \multicolumn{3}{c|}{ \% Difference } \\
\cline { 2 - 5 } & All & Acreage & All & Acreage & Acreage \\
\cline { 2 - 5 } & 1375 & 1261 & & & -23.4 \\
\hline \hline AST Upper Cover & 1288 & 1176 & & & -44.7 \\
\hline AST Lower Cover & 1250 & 1137 & -9.08 & -9.90 & -30.9 \\
\hline PRSEUS Baseline Upper Cover & 1176 & 1064 & -8.67 & -9.54 & -50.0 \\
\hline PRSEUS Baseline Lower Cover & 1263 & 1150 & -8.13 & -8.86 & -30.1 \\
\hline PRSEUS Final Upper Cover & 1182 & 1069 & -8.27 & -9.11 & -49.7 \\
\hline PRSEUS Final Lower Cover & & 1646 & & & \\
\hline Metallic Upper Cover* & & 2127 & & & \\
\hline Metallic Lower Cover* & & & & \\
\hline
\end{tabular}

* Estimated based on data in Refs. 3 and 4. 

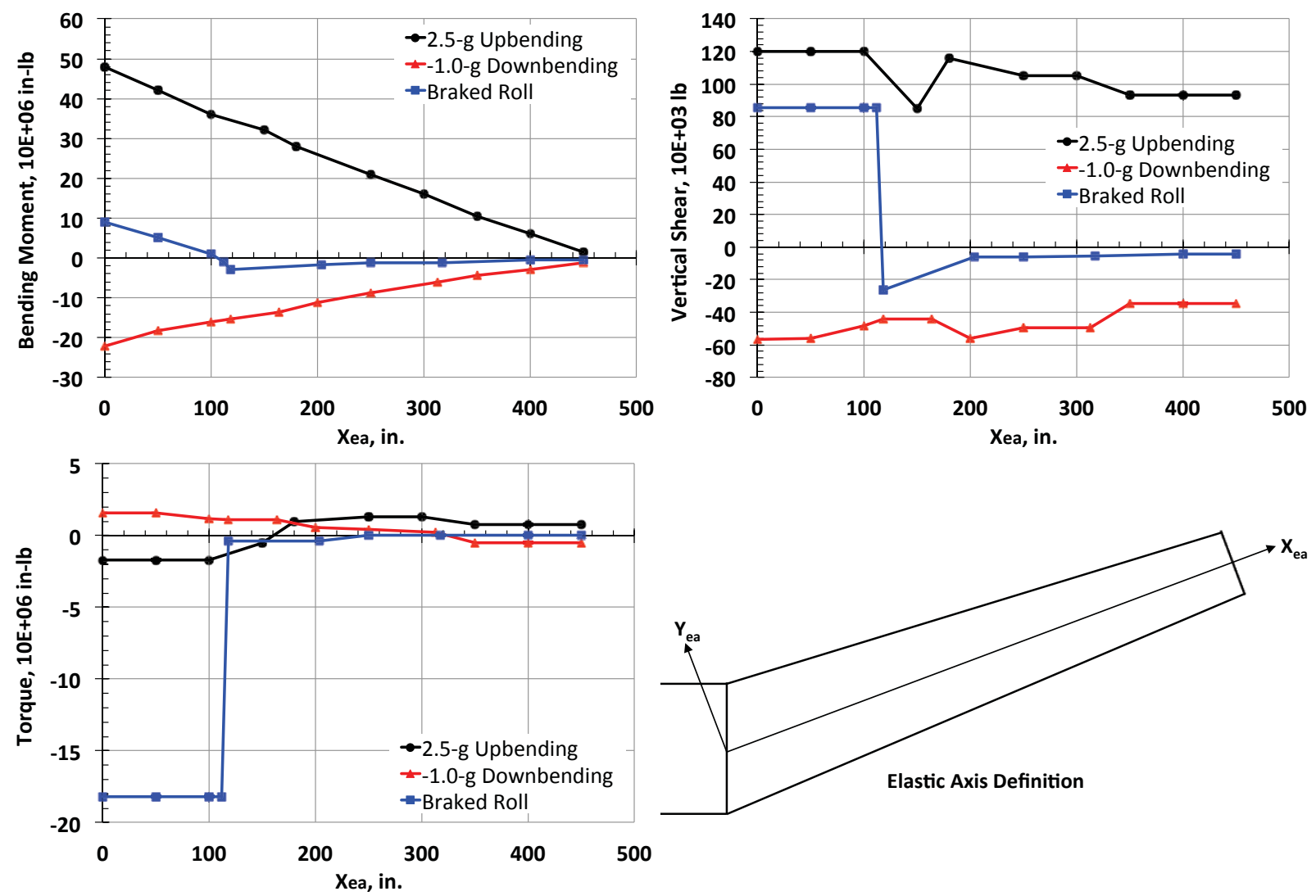

Figure 1. Semi-span DLL values used in the PRSEUS design study.

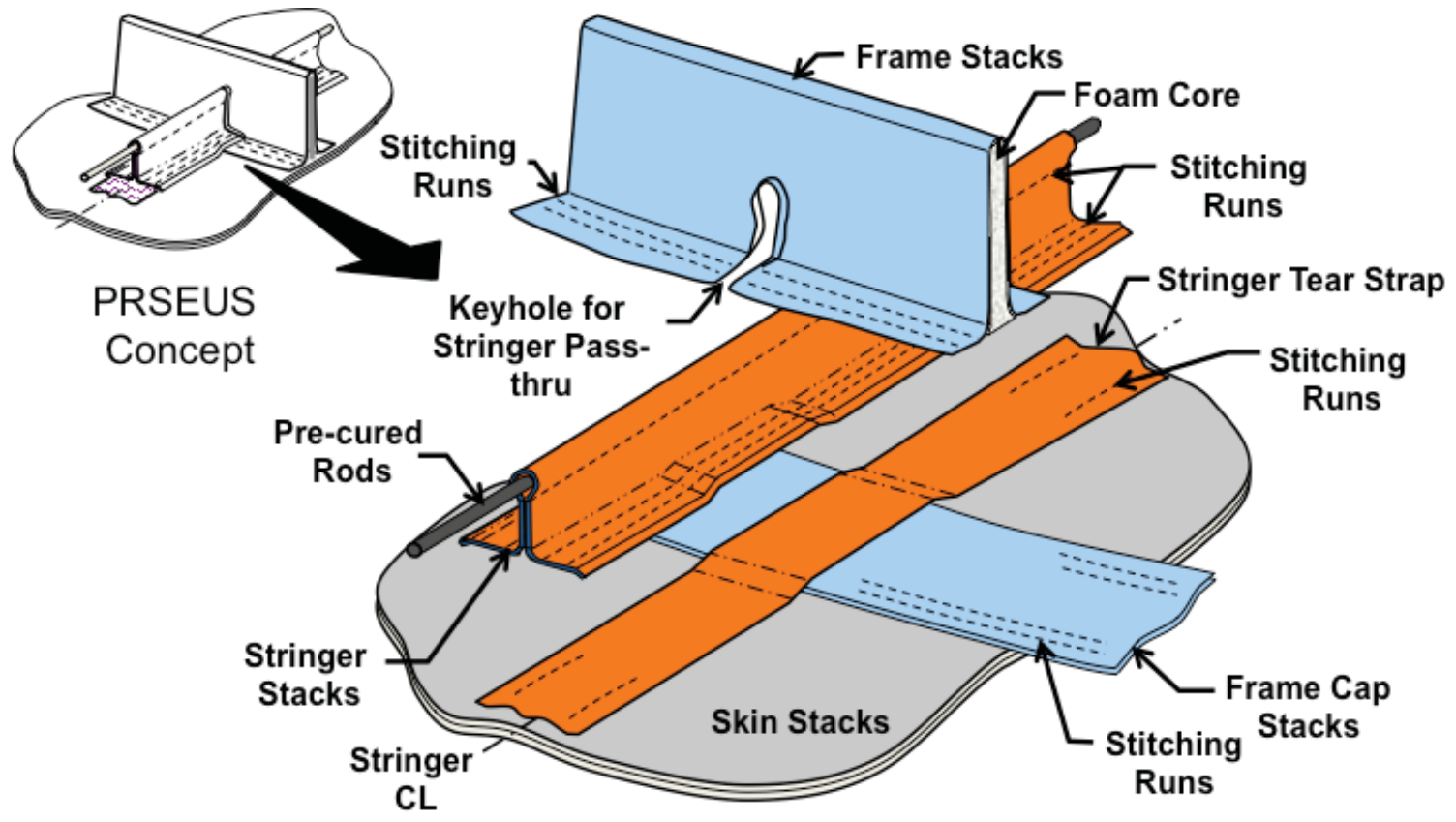

Figure 2. Typical PRSEUS concept. 


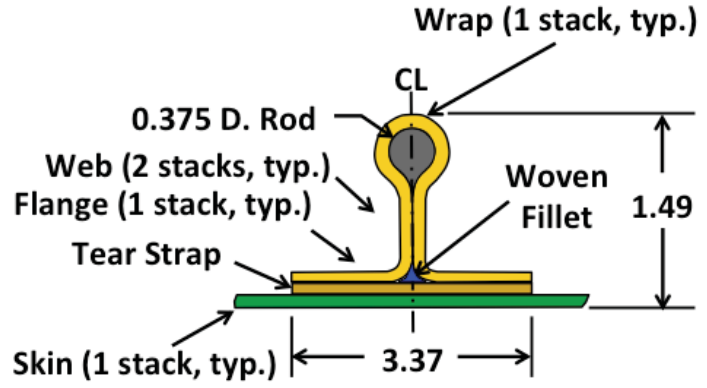

a) Stringer

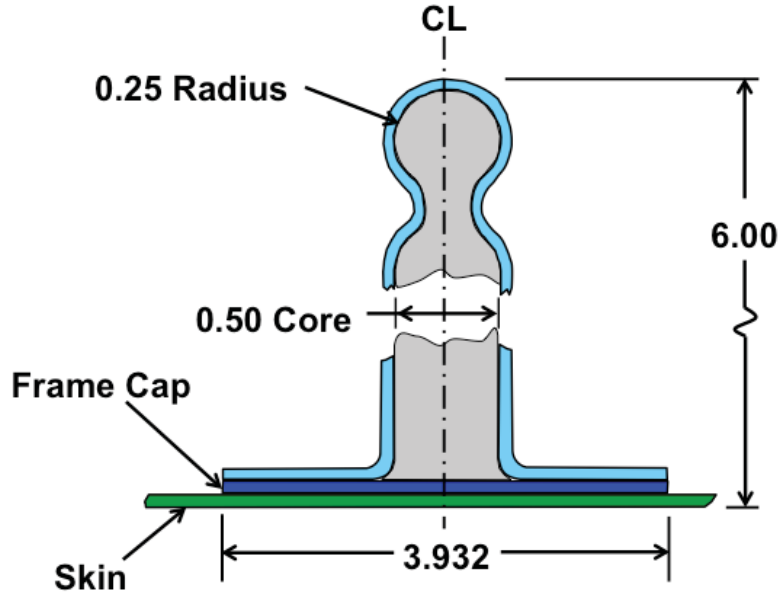

b) Frame

Figure 3. Typical pressurized HWB fuselage a) Stringer and b) Frame cross-sections with typical stack values shown for the stringer. Dimensions are in inches.

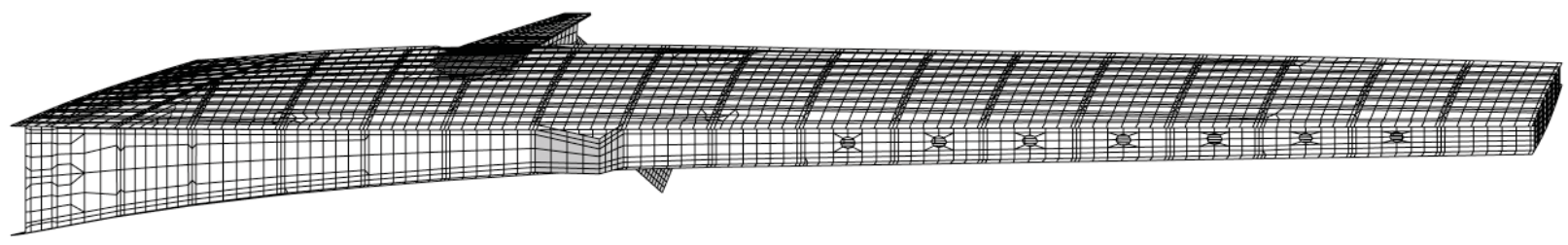

Figure 4. AST wing finite element model.

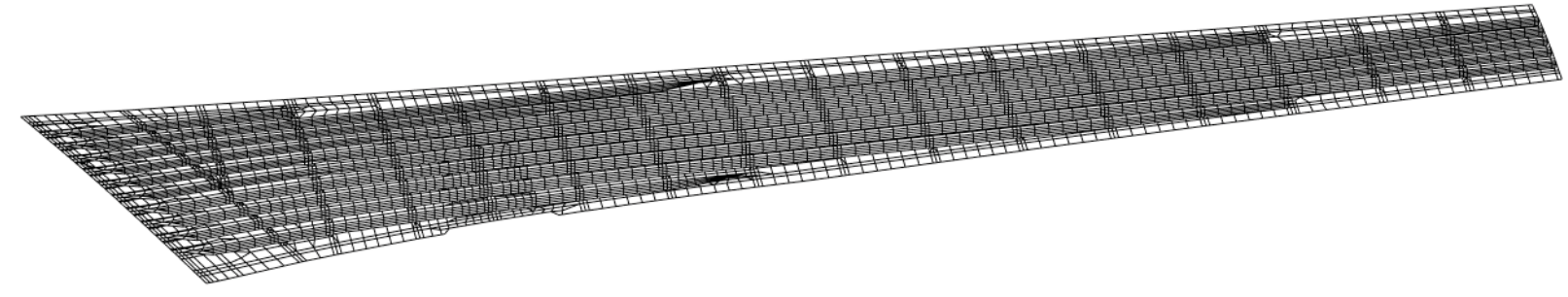

a) Upper cover

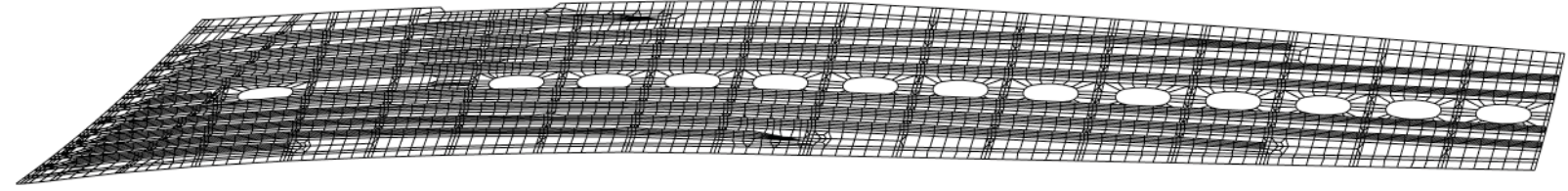

b) Lower cover

Figure 5. Finite element models of the a) Upper and b) Lower cover skins and stringers sized in PRSEUS study. 


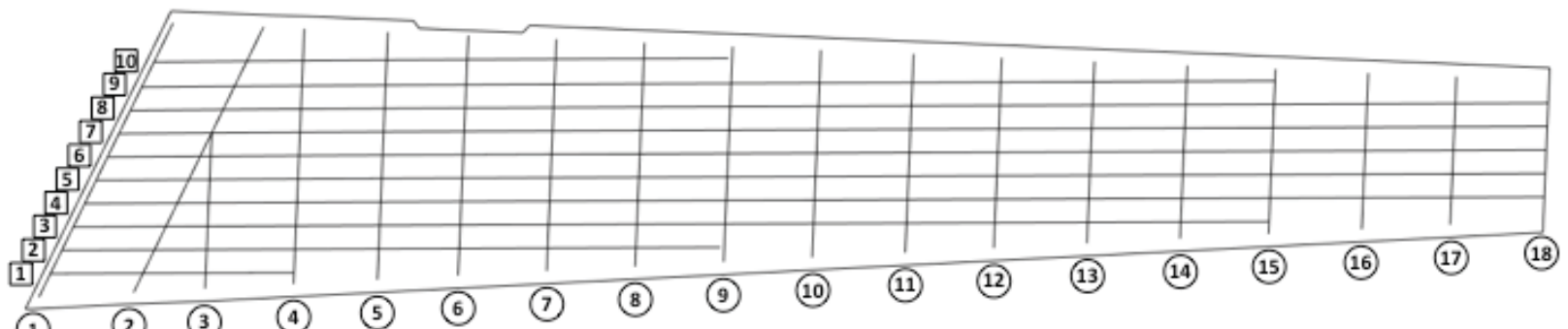

a) Upper cover

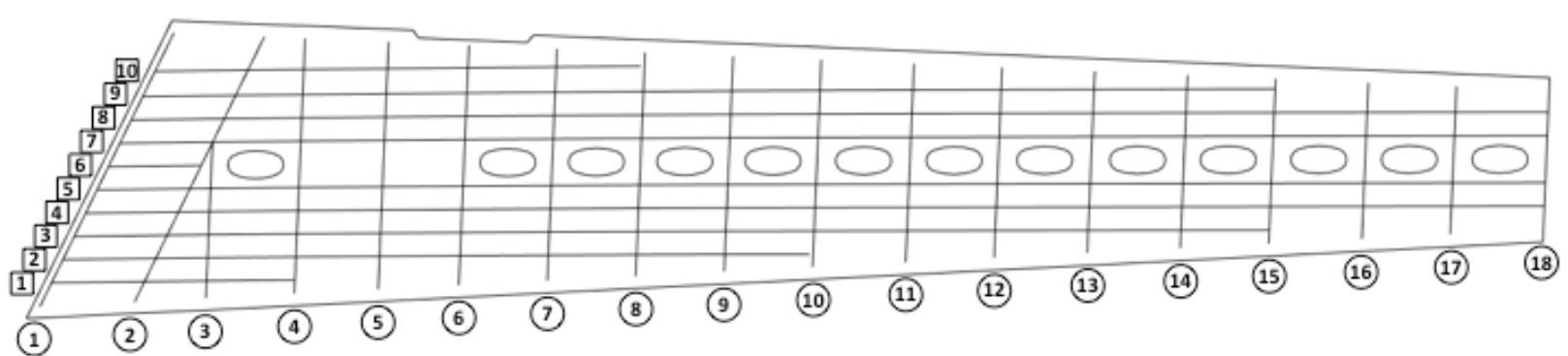

b) Lower cover

Figure 6. Schematics of the a) Upper and b) Lower cover stringer (square) and rib (circle) identification.

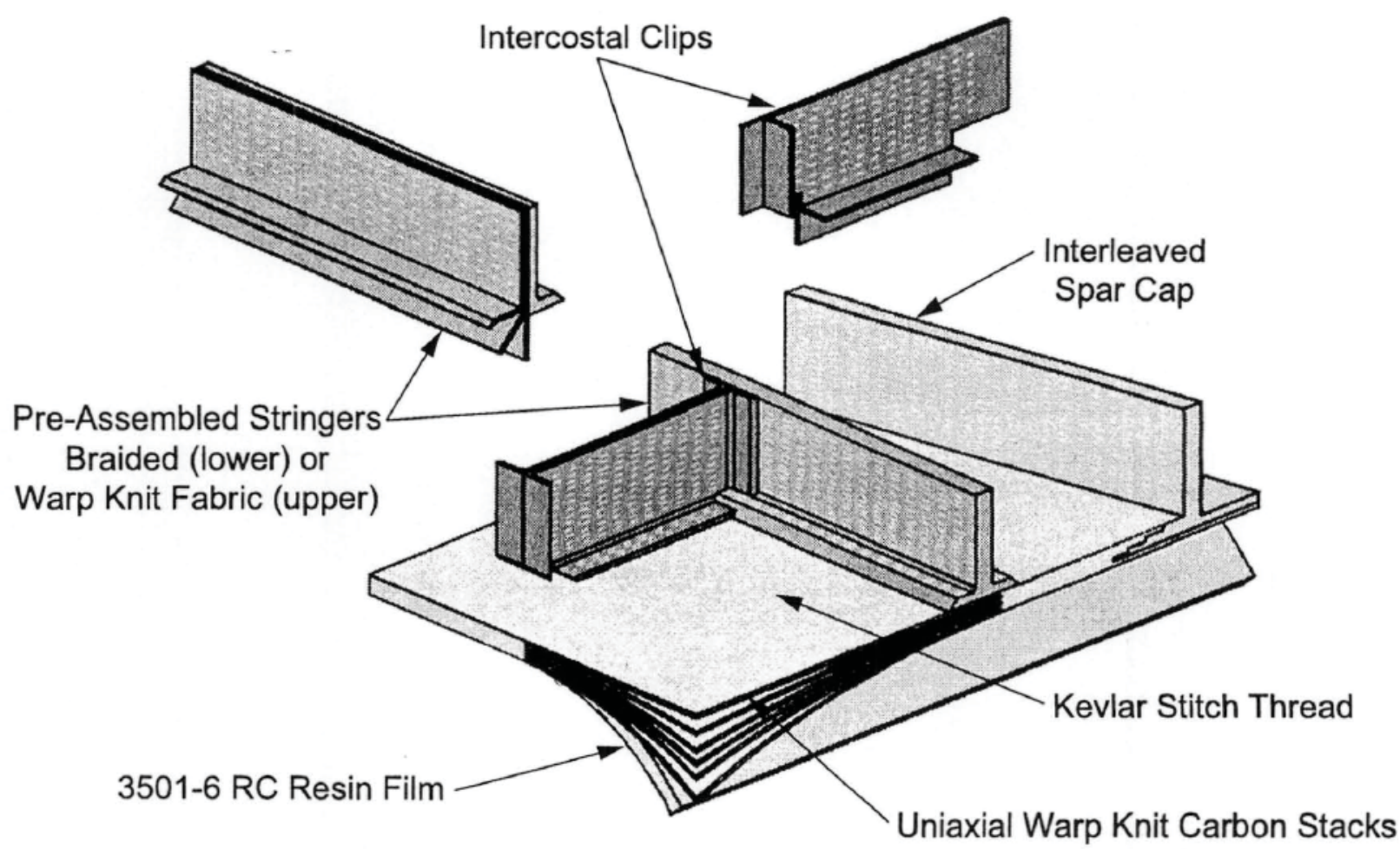

Figure 7. AST semi-span wing cover construction (from Ref. 3) 


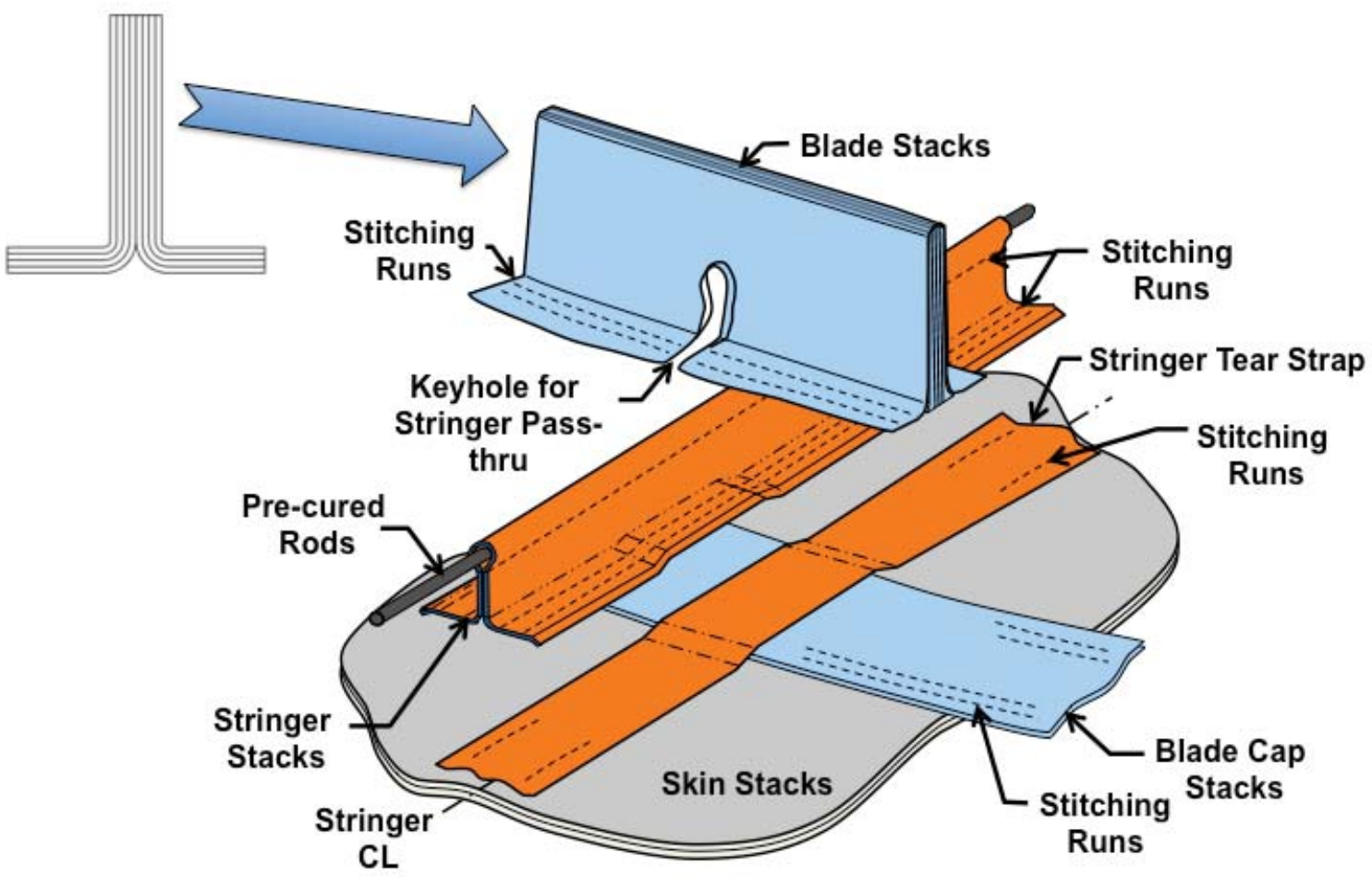

Figure 8. PRSEUS concept for wing covers.

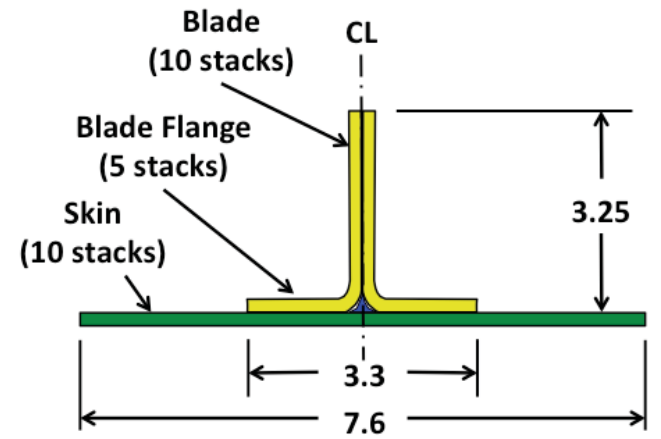

a) AST blade

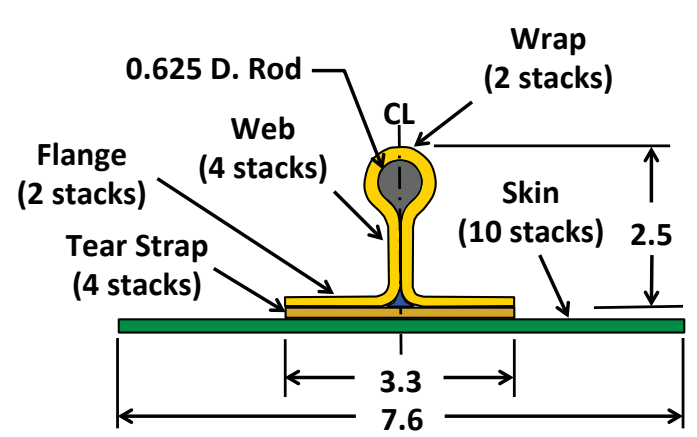

b) PRSEUS

Figure 9. Sketches (not to scale) of equivalent stiffness regions for a) AST blade and b) PRSEUS skin/stringer construction. Location is upper cover, stringer 5, between ribs 8 and 9. Weight savings approximately $13 \%$. Dimensions are in inches. 


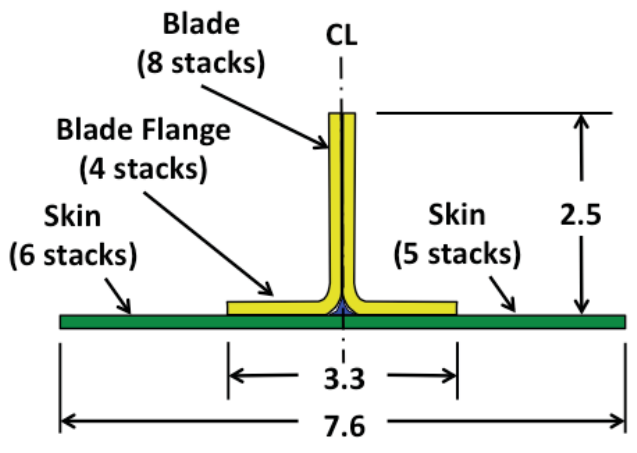

a) AST blade

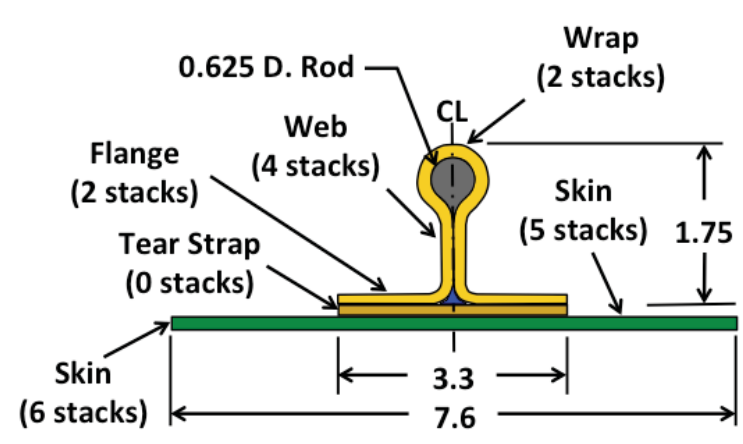

b) PRSEUS

Figure 10. Sketches (not to scale) of equivalent stiffness regions for a) AST blade and b) PRSEUS skin/stringer construction. Location is upper cover, stringer 5, between ribs 17 and 18 . Weight savings approximately $8 \%$. Dimensions are in inches. 

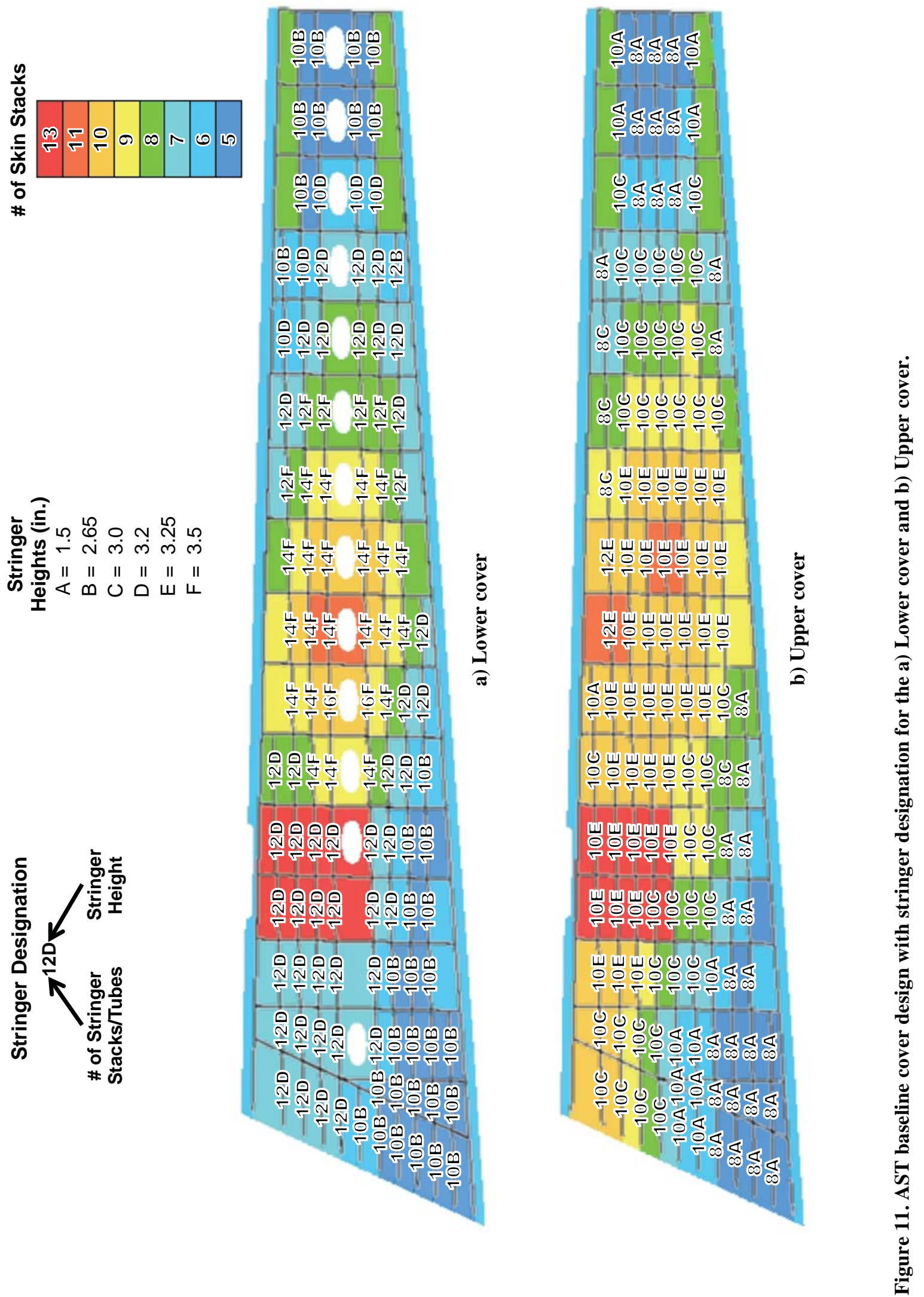


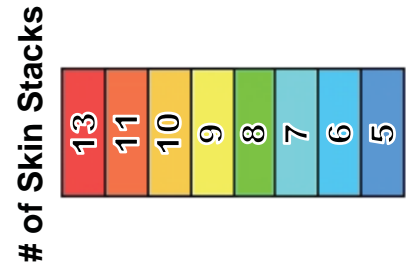

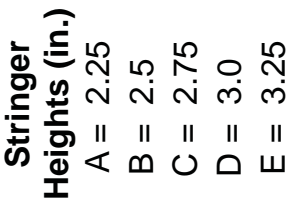

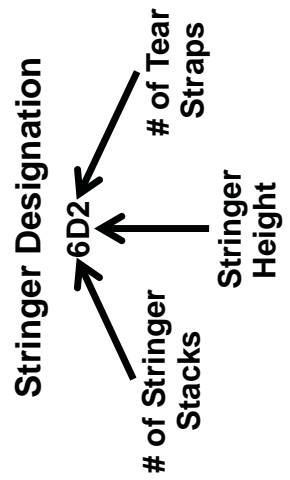

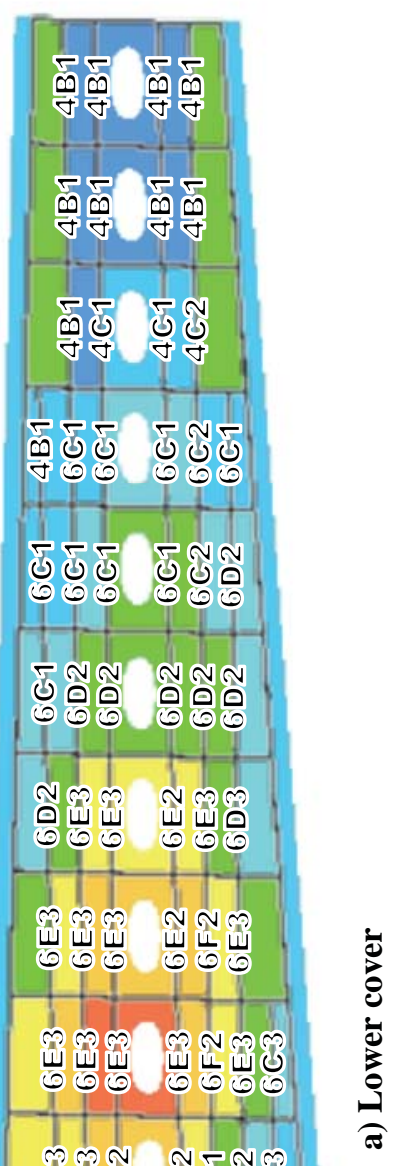

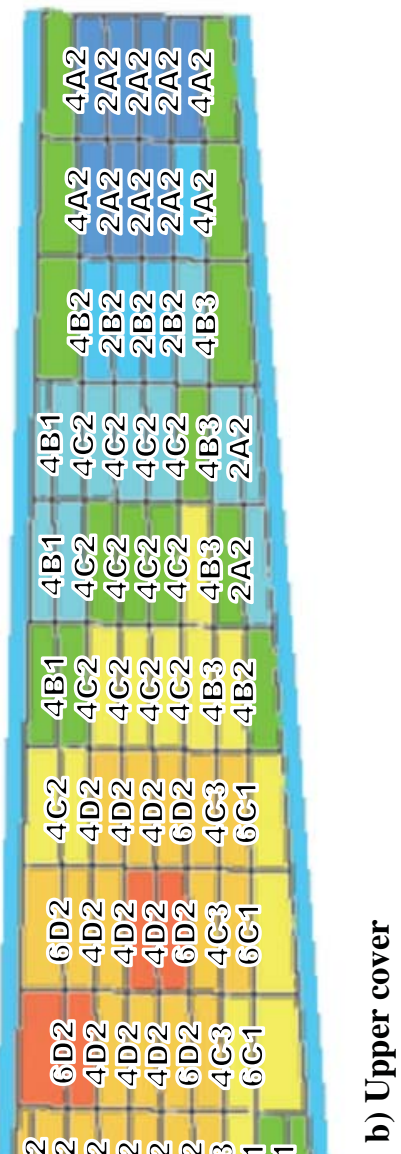

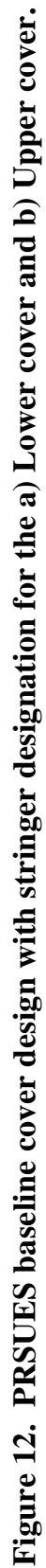




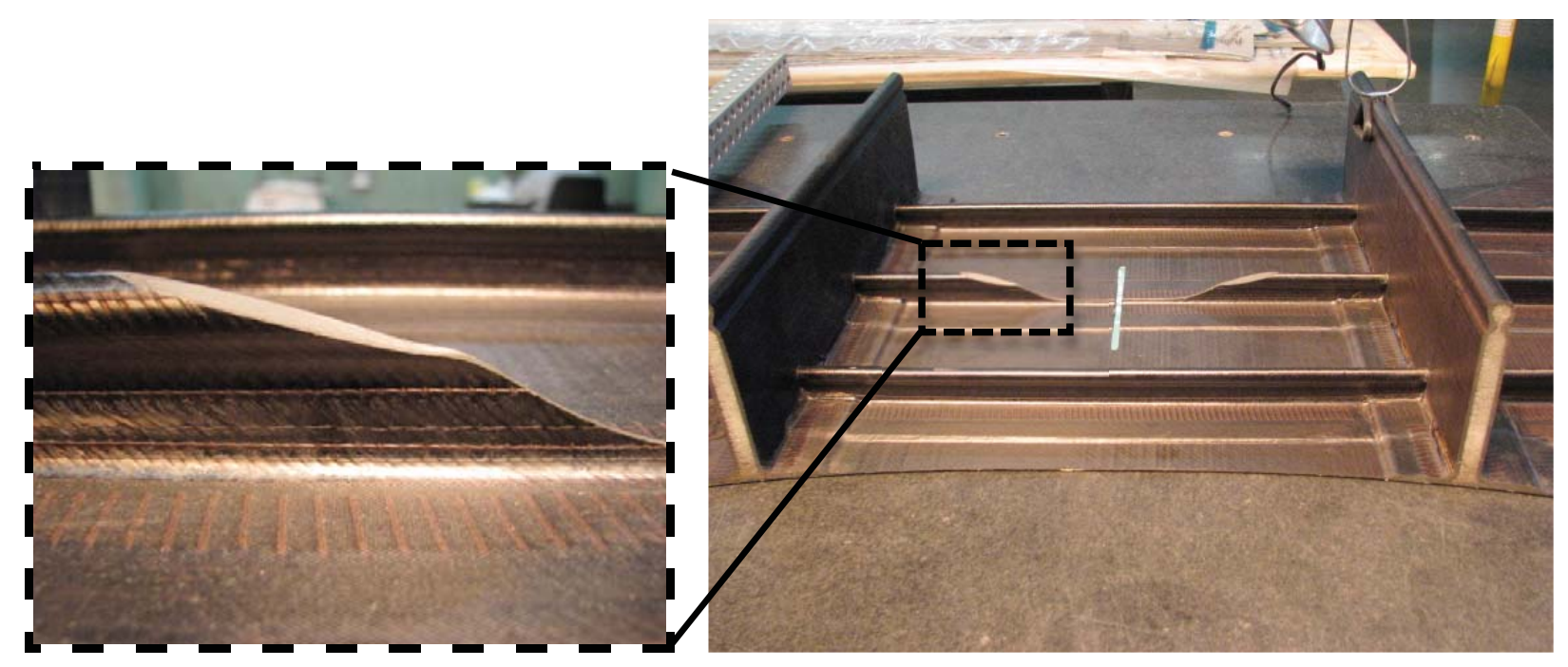

a) Detail of stringer termination taper

b) Stringer terminations in a bay

Figure 13. Approach for PRSEUS a) Detail stringer termination taper and b) Stringer terminations in a bay, based upon Ref. 8 .

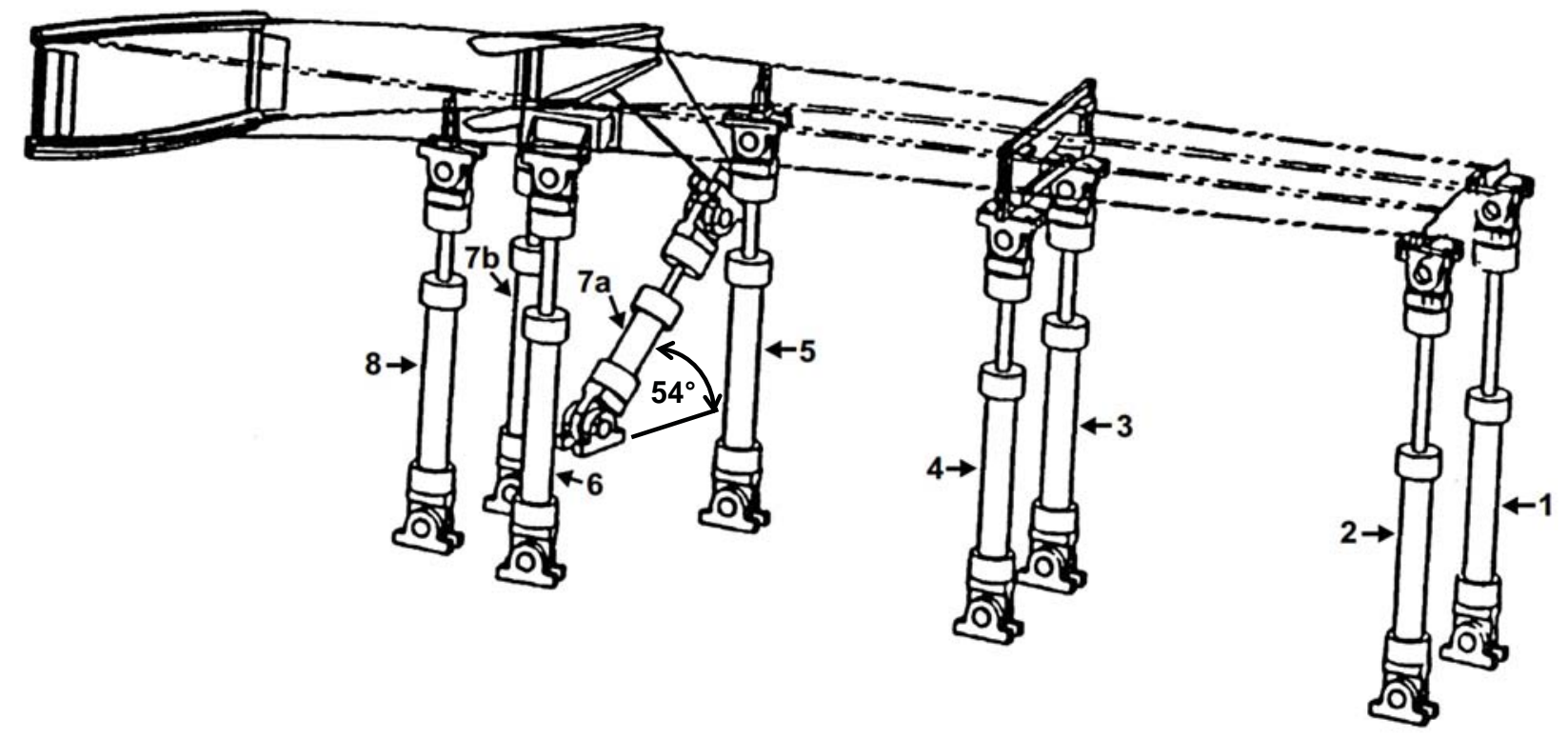

Figure 14. AST semi-span test load actuator numbering and locations. 


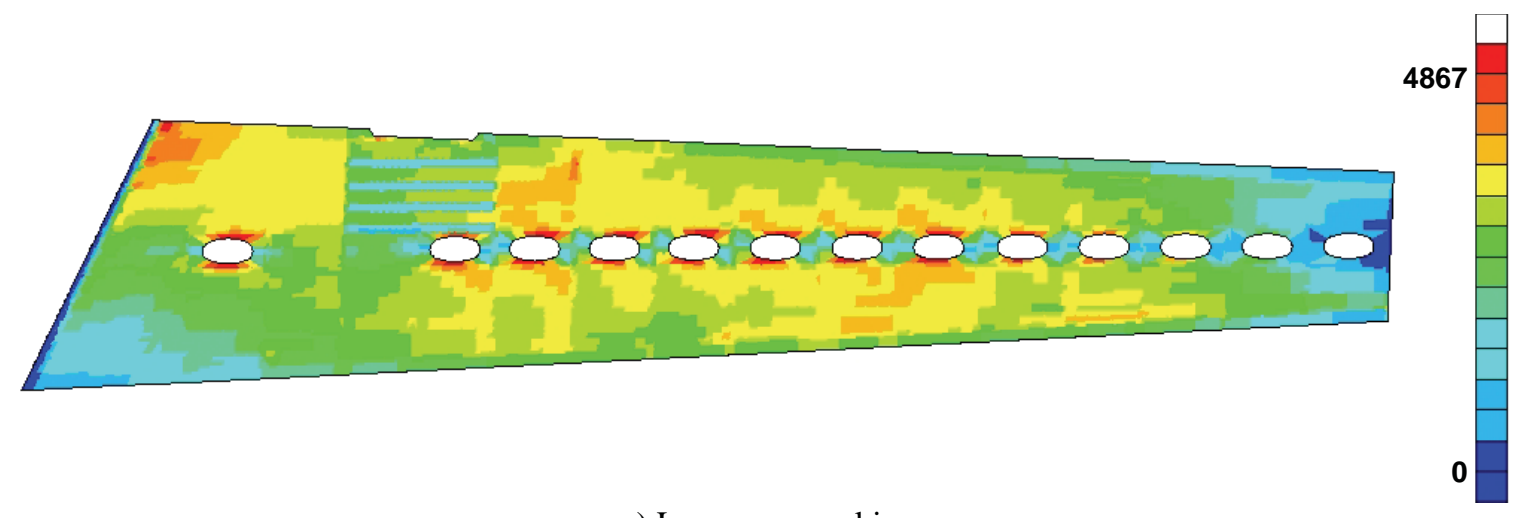

a) Lower cover skin

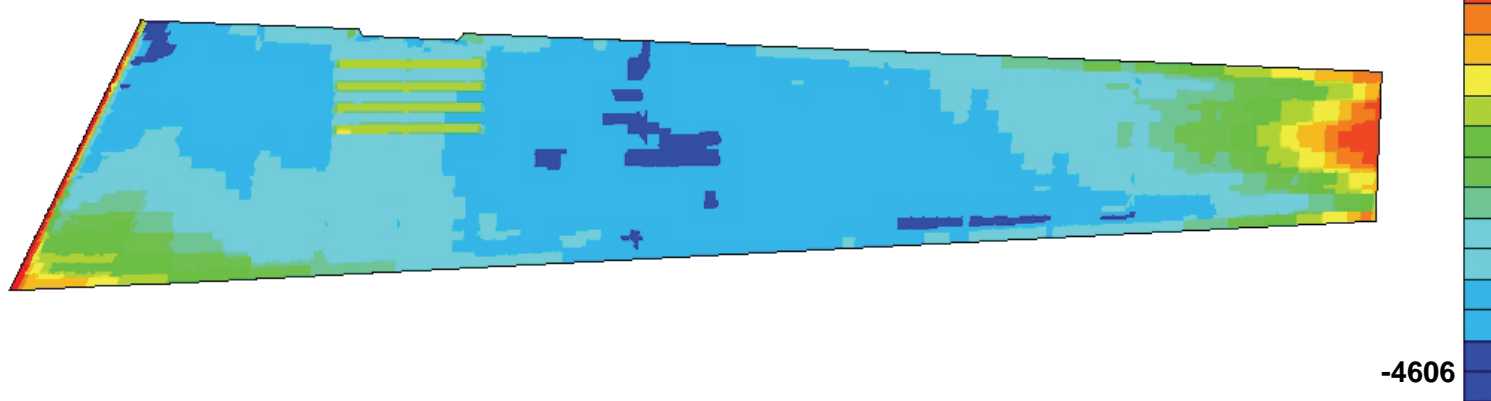

b) Upper cover skin

Figure 15. AST semi-span principal strains, in micro-in./in., 2.5G up bending load case a) lower cover skin maximum principle strains and b) upper cover skin minimum principle strains. 


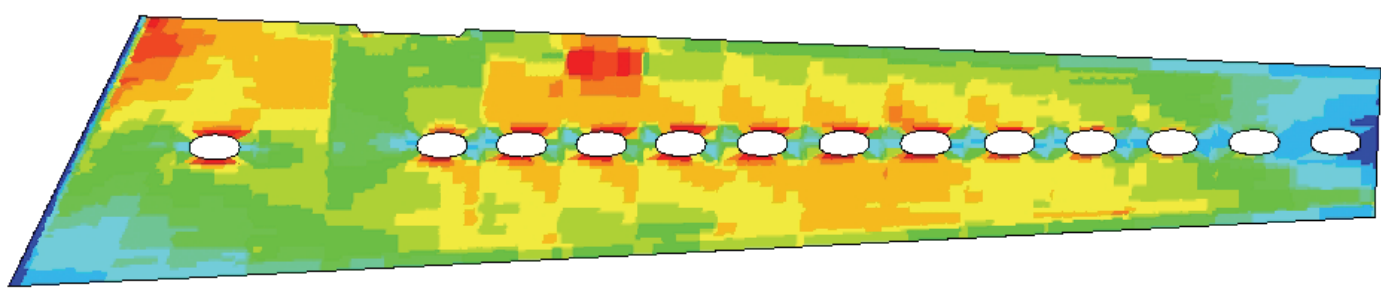

0

a) Lower cover skin

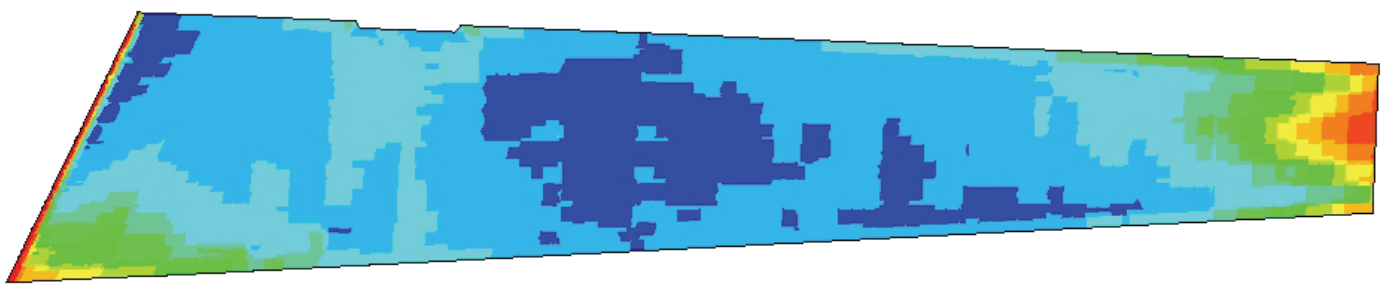

b) Upper cover skin

Figure 16. PRSEUS baseline semi-span principal strains, in micro-in./in., 2.5G up bending load case a) Lower cover skin maximum principle strains and b) Upper cover skin minimum principle strains.

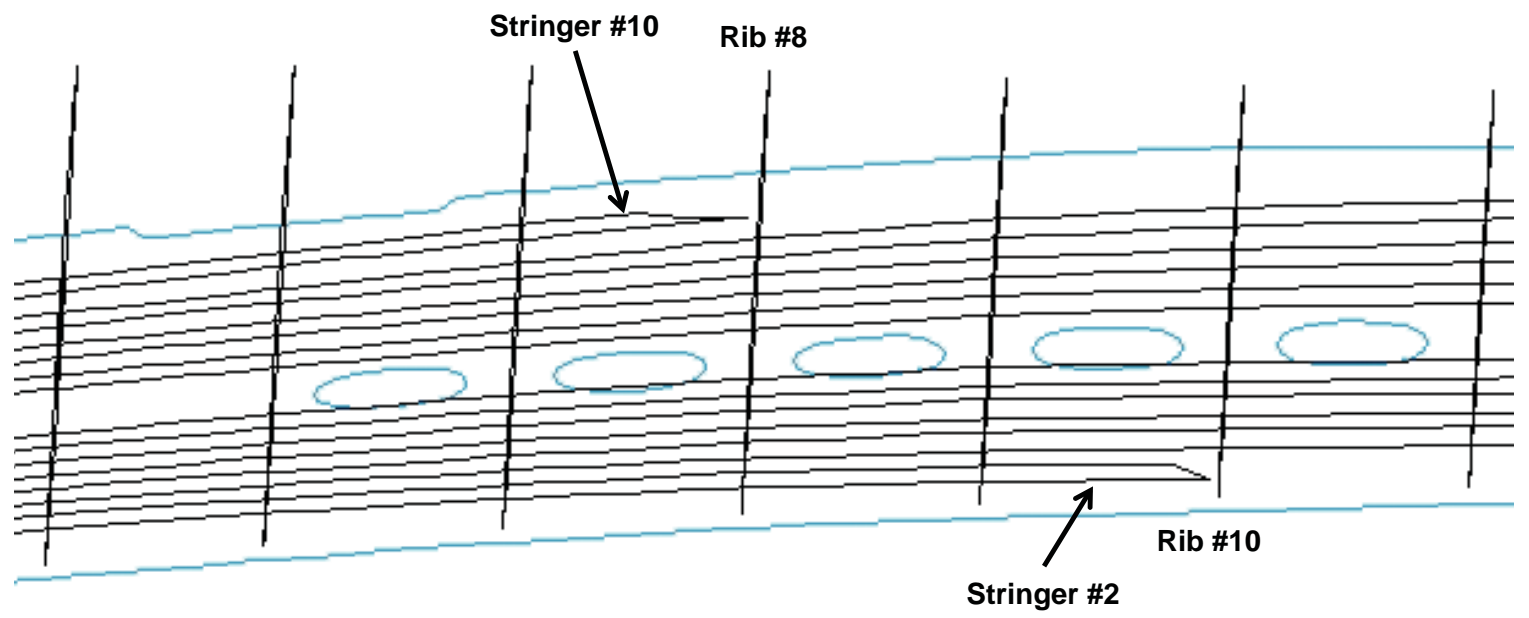

Figure 17. PRSEUS lower cover stringer runouts. 


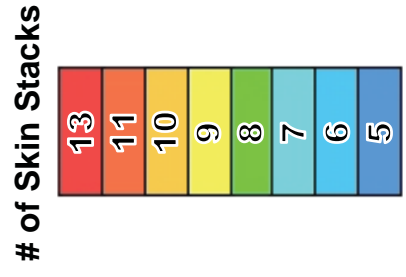

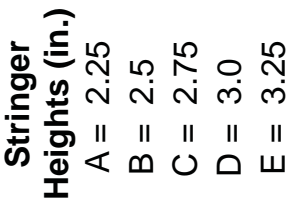

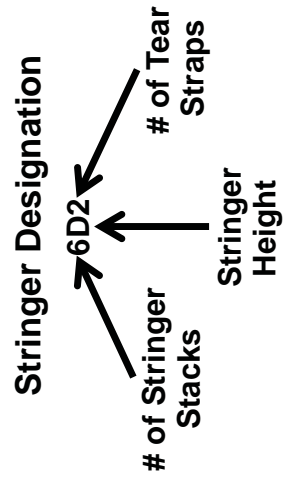

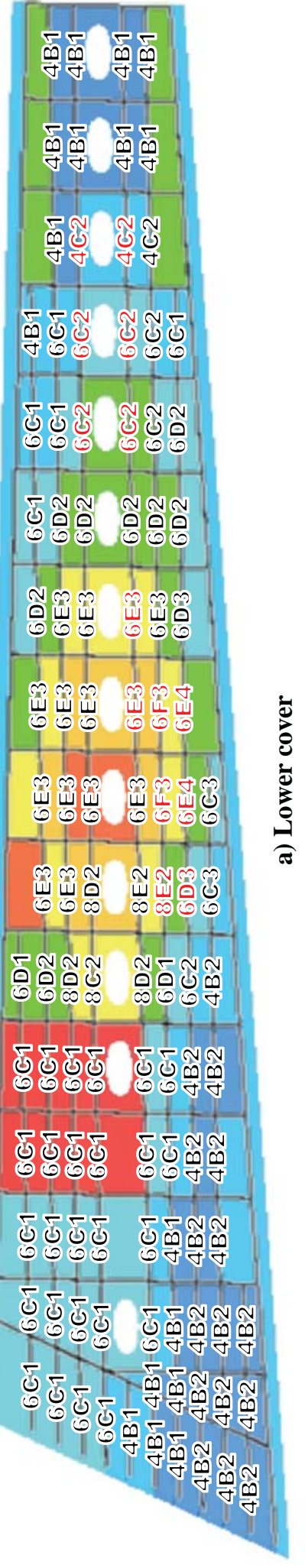

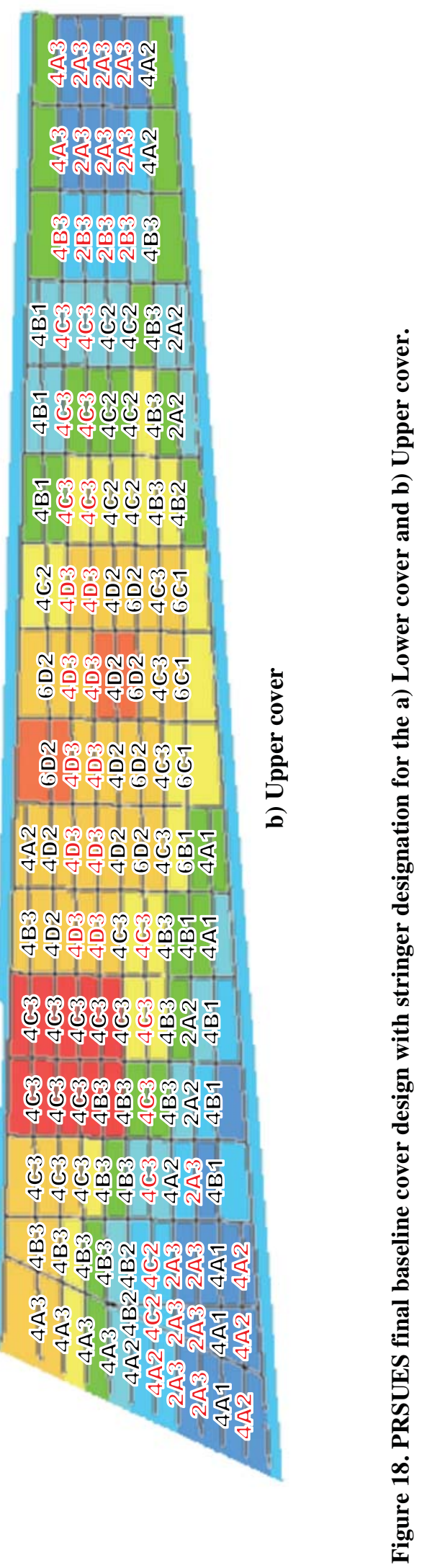



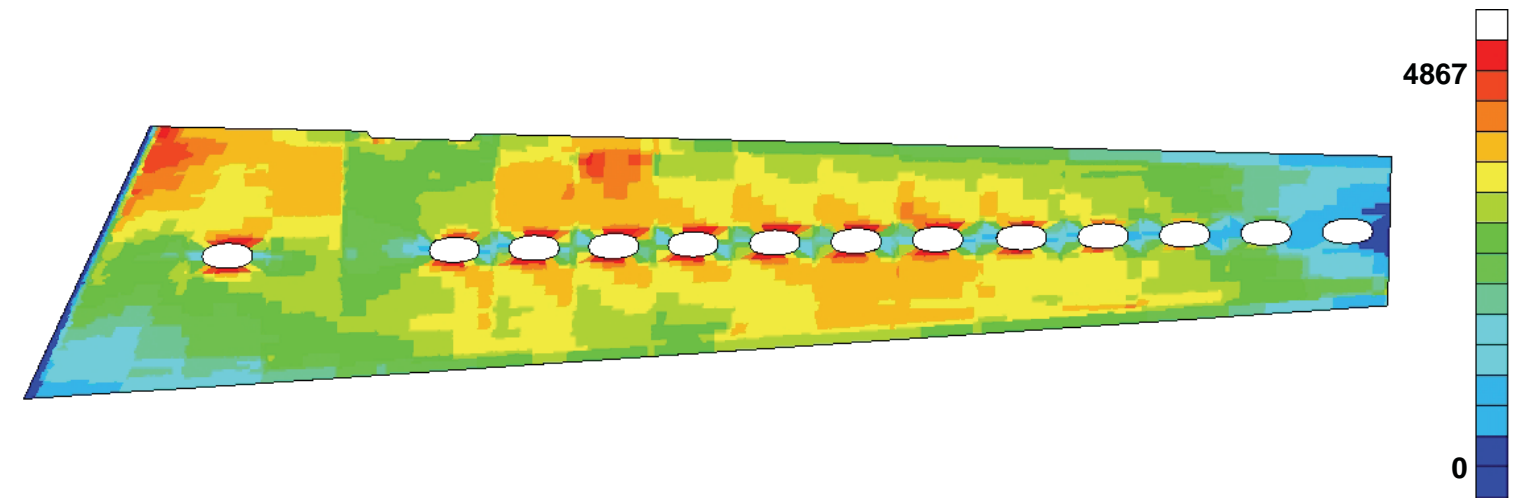

a) Lower cover skin

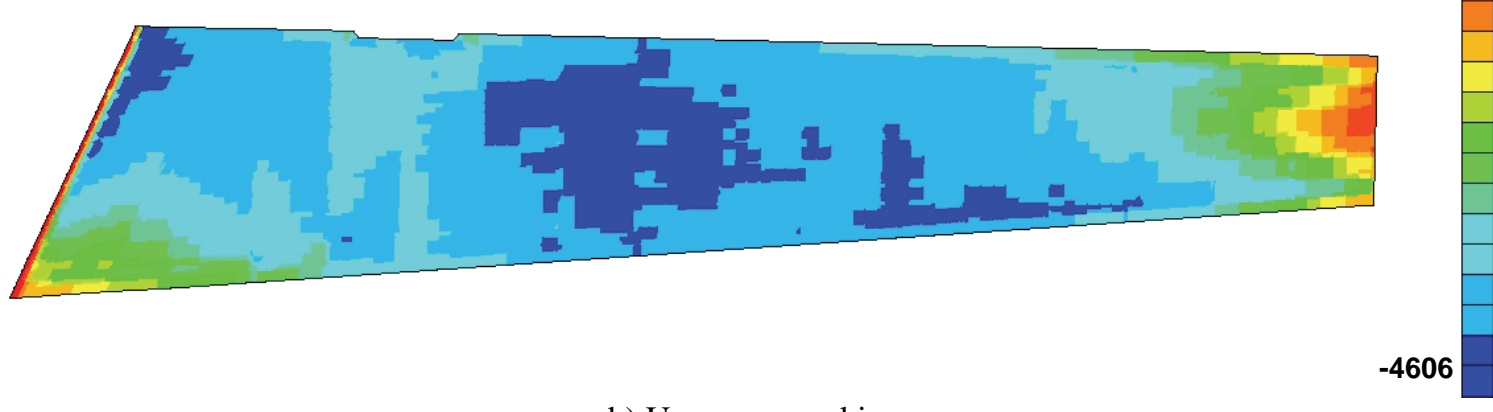

b) Upper cover skin

Figure 19. PRSEUS final design semi-span principal strains, in micro-in./in., 2.5G up bending load case a) Lower cover skin maximum principle strains and b) Upper cover skin minimum principle strains. 